\title{
Benzoylation of Amines sans Alkali: A Green Protocol in Neat Phase
}

\author{
Somnath Ghosh and Jhantu Das \\ Department of Chemistry, Jadavpur University, Kolkata 700032, India \\ Correspondence should be addressed to Somnath Ghosh, ghoshsn@yahoo.com \\ Received 9 September 2010; Revised 10 November 2010; Accepted 19 November 2010 \\ Academic Editor: Kirpal Bisht \\ Copyright () 2010 S. Ghosh and J. Das. This is an open access article distributed under the Creative Commons Attribution License, \\ which permits unrestricted use, distribution, and reproduction in any medium, provided the original work is properly cited.
}

A new procedure for benzoylation of aromatic and aliphatic amines has been developed in neat phase without use of any solvent or alkali.

Protection of functional groups such as amines, phenols, and alcohols is very often employed for multistep reactions and also needed for characterization, resolution, and purification of the said compounds as well. In this respect, benzoylation of aromatic primary or secondary amines $[1,2]$ or phenols in the presence of alkali [3-5] using commonly available benzoyl chloride is a very attractive and handy methodology known as Schotten-Baumann reaction. [6] However, the product is usually contaminated with traces of benzoyl chloride that requires crystallization from methanol, ethanol, or rectified spirit so as to convert the adhering acid chloride to its ester. Apart from benzoyl chloride, a host of reagents like benzoyl cyanide, [7] benzoic anhydride, [8] $N$-benzoyltetrazole, $[9,10]$ or 2-benzoylthio1-methylpyridinium chloride [11] has also been used. The reaction has also been performed in the presence of pyridine, triethyl amine, sodium hydride [12-15], and so forth, and also in solvent-free condition [16-29]. Recently, it has been reported [30] that an acetone solution of amine or amino acids and benzoyl chloride taken in conjunction with brine, when poured over sodium bicarbonate solution gave the benzoylated product.

We wish to report herein an absolutely solvent free green methodology for the benzoylation of both aromatic and aliphatic amines (primary and secondary) that is devoid of using any alkali and other bases. The overall process affords the product of high purity and in very high yields and in a very short time.
In a typical experimental procedure, exactly equimolar quantities $(10 \mathrm{mmol})$ of amine (primary or secondary) and benzoyl chloride are mixed in neat phase in a small beaker and stirred with a glass rod in a hood. The reaction mixture instantaneously becomes hot with the evolution of $\mathrm{HCl}$ gas and becomes a solid mass or paste that in all likelihood remains as a complex adhering with any unreacted benzoyl chloride or with any hydrochloride formed in situ. Crushed ice (ca. $10 \mathrm{gm}$ ) is then added to the contents of the beaker and stirred well with a glass rod. The thick reaction mixture gradually becomes soft, and product begins to deposit on the walls of the beaker by the dissolution of any hydrochloride adhered with the product or by the gradual dispersion of traces of benzoyl chloride in the aqueous phase during stirring, and finally the supernatant aqueous layer becomes clear when the precipitation of the product is complete as a crystalline product. The product is filtered and washed with water to free it from any adhering amine hydrochloride. It is then dried over anhydrous sodium sulphate and further crystallized from suitable solvents to obtain the benzoylated product in high yield (Table 1 ). The reaction time usually varies on an average from 3-5 min for aromatic, heterocyclic, aliphatic, and alicyclic primary amines.

While the primary amines react easily with benzoyl chloride, the secondary amines are reluctant to react under the same condition, and the time required for secondary amines is about $20-25 \mathrm{~min}$. By this protocol, only diphenyl amine (entry 19) and morpholine (entry 20) could be 
TABLE 1: Results of benzoylation of amines in neat phase (solvent-free condition) sans base ${ }^{\#}$.

\begin{tabular}{|c|c|c|c|c|c|}
\hline Entry & Substrate & Product & Yield $^{\mathrm{a}}(\%)$ & $\mathrm{mp}^{\circ} \mathrm{C}$ (lit. [31] $\left.\mathrm{mp}^{\circ} \mathrm{C}\right)$ & Time (min) \\
\hline 1 & Aniline & Benzanilide & 92 & $164(163)$ & 3 \\
\hline 2 & 2-Methylaniline & 2-Methylbenzanilide & 76 & $142(143)$ & 3 \\
\hline 3 & 3-Methylaniline & 3-Methylbenzanilide & 91 & $125(125)$ & 3 \\
\hline 4 & 4-Methylaniline & 4-Methylbenzanilide & 89 & $157(158)$ & 3 \\
\hline 5 & 2-Chloroaniline & 2-Chlorobenzanilide & 95 & $99(100)$ & 3 \\
\hline 6 & 3-Chloroaniline & 3-Chlorobenzanilide & 76 & $121(120)$ & 3 \\
\hline 7 & 4-Chloroaniline & 4-Chlorobenzanilide & 95 & $191(192)$ & 3 \\
\hline 8 & 3-Nitroaniline & 3-Nitrobenzanilide & 69 & $156(155)$ & 10 \\
\hline 9 & 4-Methoxyaniline & 4-Methoxybenzanilide & 92 & $153-54(154)$ & 5 \\
\hline 10 & 2-Aminobenzoic acid & 2-(N-benzamido) benzoic acid & 76 & $180(182)$ & 5 \\
\hline 11 & 4-Aminobenzoic acid & 4-(N-benzamido) benzoic acid & 73 & $>250(278)$ & 5 \\
\hline 12 & Methyl anthranilate & $N$-benzoyl methylanthranilate & 76 & $98-99(100)$ & 5 \\
\hline 13 & 1-Naphthyl amine & 1-N-benzamido-naphthalene & 66 & $159(161)$ & 3 \\
\hline 14 & 4-Amino pyridine & $N$-(4-pyridyl) benzamide & 66 & $208-209$ & 20 \\
\hline 15 & 2-Amino thiazole & $N$-(2-thiazolyl) benzamide & 70 & $150\left(152^{[30]}\right)$ & 10 \\
\hline 16 & Benzyl amine & $N$-benzyl benzamide & 88 & $105(106)$ & 3 \\
\hline 17 & Cyclohexyl amine & $N$-cyclohexyl benzamide & 86 & $147-48(148)$ & 2 \\
\hline 18 & $N, N$-dimethyl hydrazine & $N, N$-dimethyl benzamide & 75 & $166-67$ & 10 \\
\hline 19 & Diphenyl amine & $N$-benzoyl diphenyl amine & 67 & $180(182)$ & 25 \\
\hline 20 & Morpholine & $N$-benzoyl morpholine & 58 & $73(75)$ & 20 \\
\hline
\end{tabular}

"All the compounds give satisfactory spectral data (IR, NMR).

aYield refers to the combined amounts of the first and second crop of crystallized product.

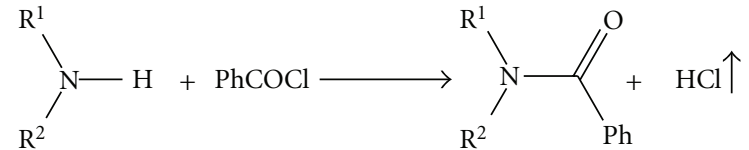

$$
\begin{aligned}
& \mathrm{R}^{1}: \mathrm{Ph}, \mathrm{R}^{2}: \mathrm{H} \\
& \mathrm{R}^{1}: \mathrm{Ar}, \mathrm{R}^{2}: \mathrm{H} \\
& \mathrm{R}^{1}: \mathrm{Het}, \mathrm{R}^{2}: \mathrm{H} \\
& \mathrm{R}^{1}: \text { Alkyl, } \mathrm{R}^{2}: \mathrm{H} \\
& \mathrm{R}^{1}: \text { Cycloalkyl, } \mathrm{R}^{2}: \mathrm{H} \\
& \mathrm{R}^{1}, \mathrm{R}^{2}: \mathrm{Ph} \\
& \mathrm{R}^{1}, \mathrm{R}^{2}:-\mathrm{CH}_{2}-\mathrm{CH}_{2}-\mathrm{O}-\mathrm{CH}_{2}-\mathrm{CH}_{2}-
\end{aligned}
$$

FIGURE 1

benzoylated. The other secondary amines such as indole, imidazole, and carbazole did not react at all with benzoyl chloride under the aforesaid condition and even on reverse addition, that is, addition of amine to benzoyl chloride failed to afford the desired product. This is because of the unavailability of lone pair on nitrogen atom that is involved in the aromaticity of the said substrates.

In this procedure, a large number of primary amines have been benzoylated in a very efficient way while the same is not much encouraging for secondary amines. The high efficacy (for primary amines) and atom economy of this methodology under solvent-free condition without use of any base or additive coupled with the isolation of the product in pure crystalline form offers an excellent improvement over the conventional methods and may be considered as a green protocol in the true sense of the meaning. The method is free from any unwanted side reactions such as hydrolysis of ester (e.g., methyl anthranilate, entry 12) or acidification (e.g., amino acids, entries 10 and 11) under the reaction condition and is the most practical and easiest way for the synthesis of $\mathrm{N}$-substituted amides in an ecofriendly condition.

\section{Acknowledgments}

Financial assistances (to J. Das) from the UGC, Government of India and the CAS, Department of Chemistry are acknowledged. 


\section{References}

[1] T. W. Greene, in Protective Groups in Organic Synthesis, pp. 261-263, Wiley, New York, NY, USA, 1981.

[2] C. B. Reese, in Protective Groups in Organic Chemistry, J. F. W. McOmie, Ed., pp. 52-53, Plenum Press, London, UK, 1973.

[3] W. Ando and H. Tsumaki, "A facile preparation of aliphatic hydroxamic acid from N,N,O-tris(trimethylsilyl)hydroxylamine and acid chloride," Synthetic Communications, vol. 13, no. 12, pp. 1053-1056, 1983.

[4] E. C. Taylor, G. W. McLay, and A. McKillop, "Thallium in organic synthesis. II. Acylation, aroylation, and tosylation of phenols and carboxylic acids," Journal of the American Chemical Society, vol. 90, no. 9, pp. 2422-2423, 1968.

[5] V. O. Illi, "Phase transfer catalyzed acylation," Tetrahedron Letters, vol. 20, no. 26, pp. 2431-2432, 1979.

[6] B. S. Furniss, A. J. Hannaford, P. W. G. Smith, and A. R. Tatchell, in Vogel's Textbook of Practical Organic Chemistry, p. 916, Pearson Education, 5th edition, 2006.

[7] F. A. Carey and K. O. Hodgson, "Efficient syntheses of methyl 2-O-benzoyl-4,6-O-benzylidene- $\alpha$-d-glucopyranoside and methyl 2-O-benzoyl-4,6-O-benzylidene- $\alpha$-d-ribohexopyranosid-3-ulose," Carbohydrate Research, vol. 12, no. 3, pp. 463-465, 1970.

[8] H. T. Clarke and E. J. Rahrs, in Organic Syntheses, Coll. Vol. I, p. 91, Wiley, New York, NY, USA, 2nd edition, 1941.

[9] J. Stawinski, T. Hozumi, and S. A. Narang, "Benzoyltetrazole: a mild benzoylating reagent for nucleosides," Journal of the Chemical Society, Chemical Communications, no. 7, pp. 243244, 1976.

[10] B. Bhat and Y. S. Sanghvi, "A mild and highly selective Nbenzoylation of cytosine and adenine bases in mucleosides with N-benzoyltetrazole," Tetrahedron Letters, vol. 38, no. 51, pp. 8811-8814, 1997.

[11] M. Yamada, Y. Watabe, T. Sakakibara, and R. Sudoh, "Preparation of a water-soluble acylating agent: benzoylation of acids, amines, and phenols with 2-benzoylthio-1-methylpyridinium chloride in aqueous phase," Journal of the Chemical Society, Chemical Communications, no. 4, pp. 179-180, 1979.

[12] S. Ghosh, T. K. Das, D. B. Datta, and S. Mehta, "Studies on enamides. Part 1: photochemical rearrangements of $\mathrm{N}$ aroylcarbazoles," Tetrahedron Letters, vol. 28, no. 39, pp. 46114614, 1987.

[13] S. Ghosh, D. B. Datta, I. Datta, and T. K. Das, "Studies on enamides. Part-2: a novel photochemical synthesis of 9H-indolo [3,2,1-de] phenanthridin-9-one, a benzcanthine analogue," Tetrahedron, vol. 45, no. 12, pp. 3775-3786, 1989.

[14] I. Datta, T. K. Das, and S. Ghosh, "Studies on enamides. Part-3 : a novel photochemical synthesis of 9-arylacridines," Tetrahedron Letters, vol. 30, no. 30, pp. 4009-4012, 1989.

[15] I. Datta, T. K. Das, and S. Ghosh, "Studies on enamides. Part4 : photochemical investigations of $\mathrm{N}$-aroyldiphenylamines," Tetrahedron, vol. 46, no. 19, pp. 6821-6830, 1990.

[16] R. S. Varma, "Solvent-free organic synthesis on mineral supports using microwave irradiation," Clean Products and Processes, vol. 1, pp. 132-147, 1999.

[17] S. Paul, P. Nanda, and R. Gupta, "PhCOCI-Py/basic alumina as a versatile reagent for benzoylation in solvent-free conditions," Molecules, vol. 8, no. 4, pp. 374-380, 2003.

[18] A. McKillop and D.W. Young, "Organic synthesis using supported reagents-part I," Synthesis, no. 6, pp. 401-422, 1979.

[19] A. McKillop and D.W. Young, "Organic synthesis using supported reagents-part II," Synthesis, no. 7, pp. 481-500, 1979.
[20] P. Laszlo, Preparative Chemistry Using Supported Reagents, San Diego, Calif, USA, Academic Press, 1987.

[21] J. H. Clark, Catalysis of Organic Reactions by Supported Inorganic Reagents, VCH, New York, NY, USA, 1994.

[22] P. Lidström, J. Tierney, B. Wathey, and J. Westman, "Microwave assisted organic synthesis-a review," Tetrahedron, vol. 57, no. 45, pp. 9225-9283, 2001.

[23] A. de la Hoz, A. Díaz-Ortis, A. Moreno, and F. Langa, "Cycloadditions under microwave irradiation conditions: methods and applications," European Journal of Organic Chemistry, no. 22, pp. 3659-3673, 2000.

[24] N. Elander, J. R. Jones, S.-Y. Lu, and S. Stone-Elander, "Microwave-enhanced radiochemistry," Chemical Society Reviews, vol. 29, no. 4, pp. 239-249, 2000.

[25] S. Deshayes, M. Liagre, A. Loupy, J. L. Luche, and A. Petit, "Microwave activation in phase transfer catalysis," Tetrahedron, vol. 55, no. 36, pp. 10851-10870, 1999.

[26] R. S. Varma, "Solvent-free organic syntheses. using supported reagents and microwave irradiation," Green Chemistry, vol. 1, no. 1, pp. 43-55, 1999.

[27] A. Loupy, A. Petit, J. Hamelin, F. Texier-Boullet, P. Jacquault, and D. Mathé, "New solvent-free organic synthesis using focused microwaves," Synthesis, no. 9, pp. 1213-1234, 1998.

[28] S. Caddick, "Microwave assisted organic reactions," Tetrahedron, vol. 51, no. 38, pp. 10403-10432, 1995.

[29] R. A. Abramovitch, "Application of microwave energy in organic chemistry-a review," Organic Preparations and Procedures International, vol. 23, no. 6, pp. 683-711, 1991.

[30] G. Chattopadhyay, S. Chakraborty, and C. Saha, "Brinemediated efficient benzoylation of primary amines and amino acids," Synthetic Communications, vol. 38, no. 23, pp. 40684075, 2008.

[31] H.T. Clarke, A Handbook of Organic Analysis: Qualitative and Quantitative, Edward Arnold, London, UK, 1952. 


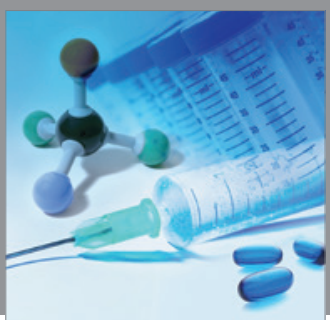

International Journal of

Medicinal Chemistry

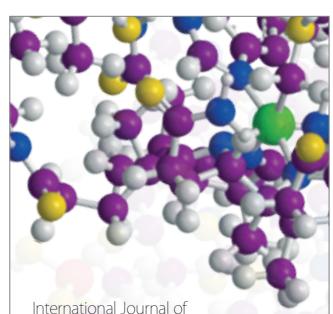

Carbohydrate Chemistry

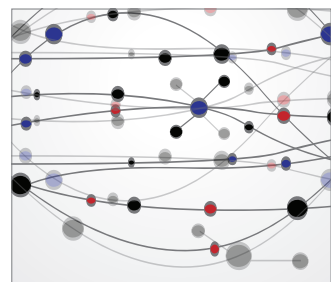

The Scientific World Journal
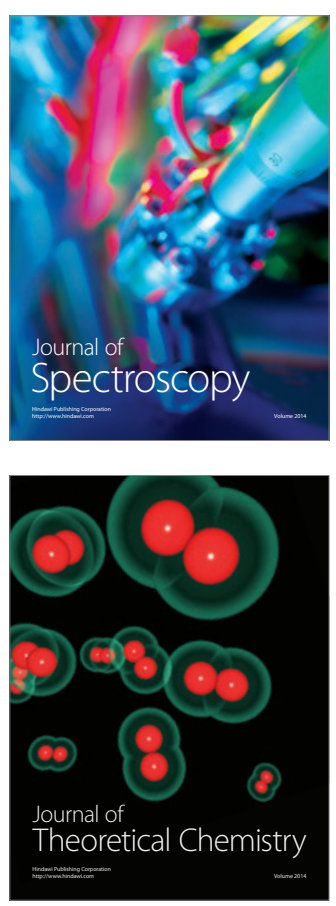
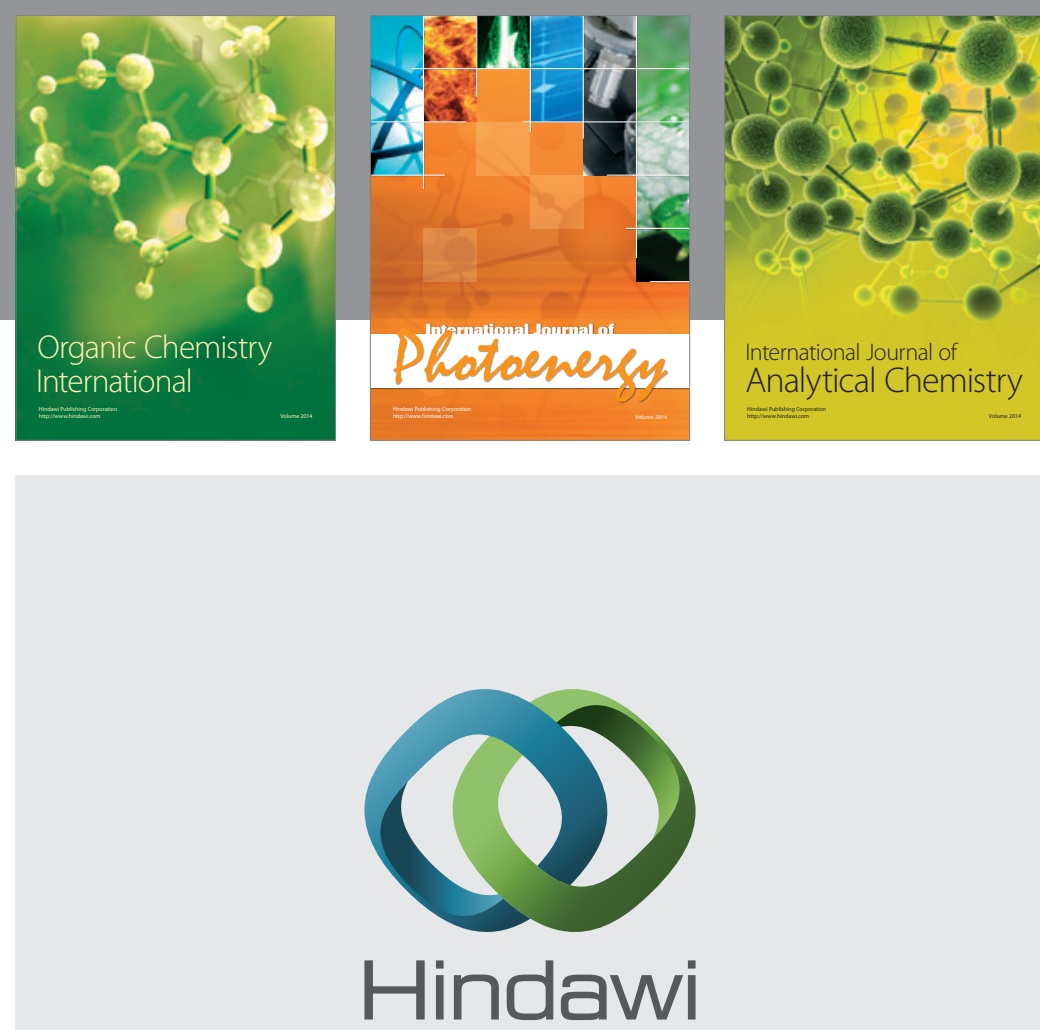

Submit your manuscripts at

http://www.hindawi.com
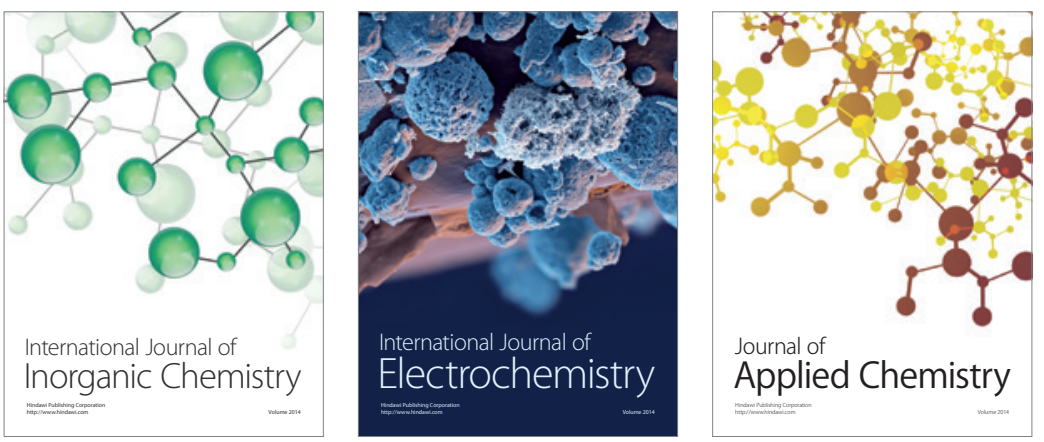

Journal of

Applied Chemistry
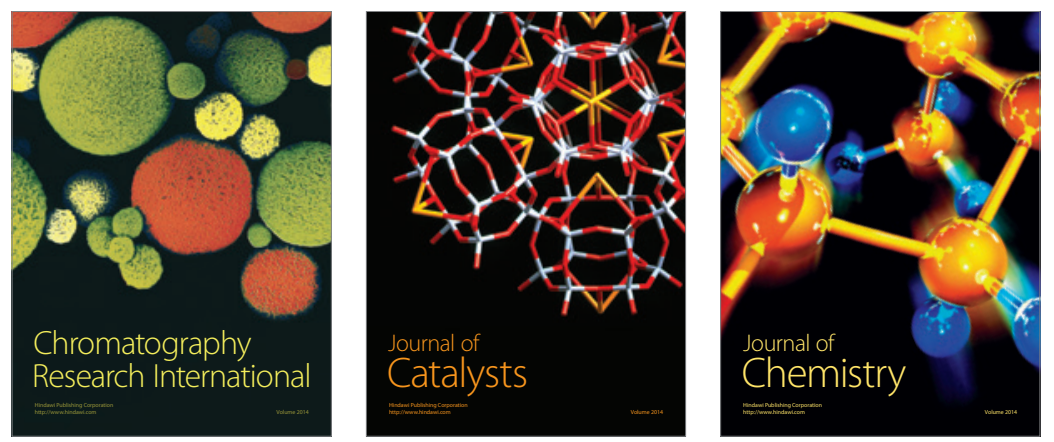
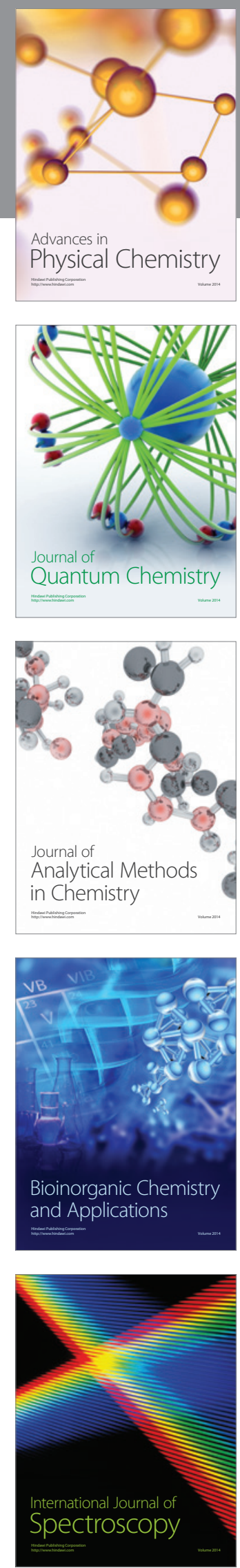